Review article

\title{
Treatment of chronic hepatitis B: Update of the recommendations from the 2007 Italian Workshop ${ }^{\text {is }}$
}

\author{
Giampiero Carosi ${ }^{\mathrm{a}, *, 1}$, Mario Rizzetto ${ }^{\mathrm{b}, 1}$, Alfredo Alberti ${ }^{\mathrm{c}, 2}$, Giuseppe Cariti $^{\mathrm{d}, 2}$, Massimo Colombo ${ }^{\mathrm{e}, 2}$, \\ Antonio Craxì $^{\mathrm{f}, 2}$, Gaetano Filice ${ }^{\mathrm{g}, 2}$, Massimo Levrero ${ }^{\mathrm{h}, 2}$, Francesco Mazzotta ${ }^{\mathrm{i}, 2}$, Giuseppe Pastore , $^{\mathrm{j}, 2}$, \\ Felice Piccinino $^{\mathrm{k}, 2}$, Daniele Prati ${ }^{1,2}$, Giovanni Raimondo ${ }^{\mathrm{m}, 2}$, Evangelista Sagnelli ${ }^{\mathrm{k}, 2}$, Mario Toti $^{\mathrm{n}, 2}$, \\ Maurizia Brunetto $^{\mathrm{o}, 3}$, Raffaele Bruno ${ }^{\mathrm{g}, 3}$, Vito Di Marco ${ }^{\mathrm{f}, 3}$, Carlo Ferrari ${ }^{\mathrm{p}, 3}$, Giovanni B. Gaeta ${ }^{\mathrm{k}, 3}$, \\ Pietro Lampertico $^{\mathrm{e}, 3}$, Alfredo Marzano ${ }^{\mathrm{b}, 3}$, Teresa Pollicino ${ }^{1,3}$, Massimo Puoti a,3, \\ Teresa Santantonio ${ }^{\mathrm{j}, 3}$, Antonina Smedile $^{\mathrm{a}, 3}$
}

${ }^{a}$ Department of Infectious and Tropical Diseases, University of Brescia, Brescia, Italy

${ }^{\mathrm{b}}$ Department of Gastroenterology, University of Turin, Turin, Italy

${ }^{c}$ Department of Histology, Microbiology and Medical Biotechnologies, University of Padova, Padova, Italy

d Department of Infectious Diseases, University of Turin, Turin, Italy

e Department of Gastroenterology, University of Milan, Milan, Italy

${ }^{\mathrm{f}}$ Department of Gastroenterology, University of Palermo, Palermo, Italy

${ }^{g}$ Department of Infectious Diseases, University of Pavia, Pavia, Italy

h Department of Internal Medicine, University of Rome La Sapienza, Rome, Italy

i Department of Infectious Diseases, S.S. Annunziata Hospital, Antella, Firenze, Italy

j Department of Infectious Diseases, University of Foggia, Italy

k Department of Infectious Diseases SUN, Napoli, Italy

${ }^{1}$ Unit of Clinical and Molecular Hepatology, Department of Internal Medicine, University of Messina, Messina, Italy

$\mathrm{m}$ Blood Center Ospedale Alessandro Manzoni, Lecco, Italy

n Department of Infectious Diseases, Grosseto Hospital, Grosseto, Italy

${ }^{\circ}$ Gastroenterology and Hepatology Unit, University Hospital of Pisa, Pisa, Italy

p Unit of Infectious Diseases and Hepatology, Azienda Ospedaliero-Universitaria di Parma, Parma, Italy

\section{A R T I C L E I N F O}

\section{Article history:}

Received 14 October 2010

Accepted 21 October 2010

Available online 26 January 2011

\section{Keywords:}

Adefovir

Cirrhosis

Entecavir

HBV

Lamivudine

Telbivudine

Tenofovir

\begin{abstract}
A B S T R A C T
The Italian recommendations for the therapy of hepatitis B virus (HBV)-related disease were issued in 2008. Subsequently in 2008 the nucleotide analogue (NA) Tenofovir was approved for antiviral treatment. The introduction of this important new drug has called for the current guidelines update, which includes some additional revisions: (a) the indication for therapy is extended to mild liver fibrosis and the indication for treatment is graded as "possible", "optional" or "mandatory" according to the fibrosis stage; (b) two different treatment strategies are described: first line definite duration treatment with interferon, long-term treatment of indefinite duration with NA; (c) the indication to follow either strategy is also based on the stage of liver fibrosis; (d) virological monitoring is modified to include the definitions of failure and of sustained virological response to interferon therapy; (e) the recommendation to use HBV DNA assays with high sensitivity and wide linear ranges is underlined (f) guidelines on post-treatment follow-up after finite treatment with NA, potential side effects of therapy and non-virological monitoring are defined; (g) definitions and treatment of patients without optimal response to NA are reported; (f) treatment and monitoring of compensated or decompensated cirrhosis and hepatocellular carcinoma are updated.
\end{abstract}

(c) 2010 Editrice Gastroenterologica Italiana S.r.l. Published by Elsevier Ltd. All rights reserved.

\footnotetext{
放 With the Endorsement of: Italian Association for the Study of The Liver (Associazione Italiana per lo Studio del Fegato, AISF), Secretaries: Daniele Prati and Raffaele

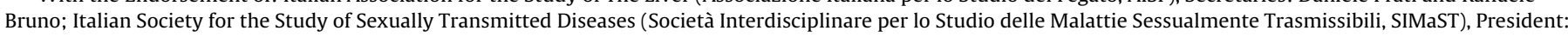
Giampiero Carosi and Italian Society of Infectious and Tropical Diseases (Società Italiana Malattie Infettive e Tropicali, SIMIT) Presidents: Francesco Mazzotta and Evangelista Sagnelli.

* Corresponding author at: Department of Infectious Diseases, University of Brescia, AO Spedali Civili, P.zzle Spedali Civili 1, 25123 Brescia, Italy. Tel.: +39 0303995671; fax: +39030303061.

E-mail address: carosi@bsnet.it (G. Carosi).

1 Authors.

2 Jury.

3 Expert Panel.
} 
Table 1

Compounds that are currently licensed in Italy for the treatment of chronic hepatitis B.

\author{
Interferon (IFN) alpha 2a and alpha $2 \mathrm{~b}$ \\ Lamivudine \\ Adefovir \\ Entecavir \\ Telbivudine \\ Pegylated interferon (PEG-IFN) alpha 2a \\ Tenofovir
}

\section{Introduction}

The Italian recommendations for the therapy of HBV disease were issued in 2008 following their discussion in 2007 [1]. In 2008 Tenofovir, a nucleotide antiviral efficacious in hepatitis B, was licensed and has entered clinical use (Table 1). The introduction of this important new drug has called for the current update. Two experts (AM and MP) reviewed the pertinent literature published from May 1st 2007 to August 1st 2010 (282 papers which are listed online) and proceedings presented at major International Congresses on Viral hepatitis, HIV infection and Hepatology in the years 2007, 2008, 2009 and until August 1st 2010. AM and MP drafted an update of the recommendations in accordance with the editors (GC and MR) reporting as references only a small number of the reviewed papers [2-27]. The draft was peer reviewed by the panel of experts, approved by the members of the Jury and finally edited by GC and MR. The revision evaluates the role of Tenofovir within the 2008 therapeutic scenario; included are also several new diagnostic developments fostered in the meanwhile by progress in the knowledge of hepatitis B.

The parts of the 2008 recommendations pertinent to the alternative/complementary use of Tenofovir were considered for revision. The update was carried out on the original framework of the 2008 recommendations and was circulated and approved by the same experts who elaborated the original consensus.

Limited to the new issues considered, the level of existing evidence was scored and statements were ranked as for the original 2008 Consensus (Table 2). The baseline indications on treatment strategy were given in the previous recommendations. Statements similar to the original 2008 Consensus are reported as ST1, updated new statements are reported as ST2.

Issues revised in the current ST2 document are: (a) extension of the indication for therapy to mild liver fibrosis and the indication for treatment was graded as possible, optional or mandatory

Table 2

System for ranking recommendations modified from Infectious Diseases Society of America - United States public health system grading service for ranking recommendations in clinical guidelines.

\begin{tabular}{cl}
\hline Category, grade & Definition \\
\hline $\begin{array}{c}\text { Strength of recommendation } \\
\text { A }\end{array}$ & $\begin{array}{l}\text { Good evidence to support a recommendation } \\
\text { Moderate evidence to support a } \\
\text { B }\end{array}$ \\
recommendation \\
Poor evidence to support a recommendation \\
Quality of evidence & Evidence from $>1$ properly randomized, \\
I & controlled trial \\
II & Evidence from $>1$ well-designed clinical trial, \\
& without randomization; from cohort or \\
& case-controlled analytical studies; from \\
multiple time-series, or from dramatic results \\
from uncontrolled experiments \\
Evidence from opinions of respected \\
authorities, based on clinical experience, \\
descriptive studies, or reports of expert \\
committees
\end{tabular}

according to the fibrosis stage; (b) details of two different treatment strategies: first line treatment for a definite time with interferon, long-term treatment strategy of indefinite duration with NA; (c) the indication to follow either strategy based on the stage of liver fibrosis; (d) modification of virological monitoring to include a definition of failure or sustained virologic response to interferon therapy; (e) the recommendation to use HBV DNA assays with high sensitivity and wide linear ranges; (f) definition of guidelines on post-treatment follow up after finite treatment with NA, potential side effects of therapy and non-virological monitoring; (g) definitions and treatment of patients without optimal response to NA; (f) update of treatment and monitoring of compensated or decompensated cirrhosis and hepatocellular carcinoma.

\section{Naïve patients with HBeAg positive chronic hepatitis B}

Candidates for treatment are patients with: (1) active and persistent hepatitis B virus (HBV) replication defined by HBV DNA $>20,000 \mathrm{IU} / \mathrm{mL}$ in patients with serum HBeAg for longer than 6 months (AI), and (2) ALT greater than the upper normal level (UNL) (AI) (ST2).

Patients with HBV DNA >20,000 IU/mL but with persistently normal ALT should not be treated (BII); treatment should be considered if there is significant liver fibrosis (METAVIR F2 or Ishak S3 or greater) despite normal ALT (BIII) (ST2).

Treatment (ST2):

- can be offered ("is possible") to patients with mild fibrosis (Ishak stage $<$ S3 or METAVIR stage $<$ F2) and ALT greater than the UNL,

- should be considered ("is optional") in all patients with moderate fibrosis (METAVIR $\mathrm{F} \geq 2$ or Ishak $\mathrm{S} \geq 3$ ),

- is recommended ("is mandatory") in patients with advanced liver fibrosis (METAVIR $F \geq 3$ or Ishak $S \geq 4$ ) (AII).

\subsection{How to treat and what strategy to use}

\subsubsection{Finite duration treatment (new chapter ST2)}

Sero-conversion to anti-HBe with immune control of HBV replication and the regression of necro-inflammation are the main treatment endpoints in HBeAg positive hepatitis. Finite duration treatment preferably with interferon (pegylated or not pegylated) remains the treatment of choice in non-cirrhotic HBeAg positive patients (BIII)

Non-pegylated alfa 2a and alfa $2 \mathrm{~b}$ interferons (IFN) are available, but only pegylated alfa 2a Interferon (PEG IFN) is registered for this purpose; PEG-IFN alfa 2b Interferon has shown equal efficacy in phase II studies. Pegylated Interferon alfa 2a should be used at $180 \mathrm{mcg}$ as a single dose per week for 12 months. Treatment should be stopped (after 3 months) if not tolerated or not effective at the 3rd month of therapy (less than $1 \log _{10} \mathrm{IU} / \mathrm{mL}$ decrease in HBV-DNA level from baseline).

Predictors of response to IFN are [2] baseline ALT $>5$ times the UNL, baseline HBV DNA $<20,000,000 \mathrm{IU} / \mathrm{mL}, \mathrm{HBV}$ genotype $\mathrm{A}$ or $\mathrm{B}$ (AII).

If a patient

1) has not responded to IFN therapy

2) has major contra-indications to IFN

3 ) is intolerant or unwilling to receive IFN

finite duration treatment with nucleoside/tide analogues (NA) can be considered in patients with mild fibrosis (METAVIR $\mathrm{F} \leq 1$ or Ishak $\mathrm{S} \leq 2$ ). The duration should not exceed 1 year if the clearance of HBeAg is not obtained (CIII). However, in persons treated with NAs with high genetic barrier (Entecavir or Tenofovir) treatment 
can be extended to 3 years with apparently no significant risk of resistance (BII). Safety data for longer periods are not robust enough to recommend their extended use in patients with mild fibrosis $[3,4]$ (CIII).

\subsubsection{Indefinite duration treatment}

Long-term ("indefinite duration") treatment with NAs can be considered in alternative to pegylated interferon in patients with moderate fibrosis (METAVIR $F \geq 2$ or Ishak $S \geq 3$ ); it is recommended in advanced liver disease (METAVIR $F \geq 3$ or Ishak $S \geq 4$ ) (BII). Withdrawal of NAs in patients who did not convert to anti-HBe could be dangerous for the risk of hepatitis flares (BIII).

Monotherapy with Entecavir $(0.5 \mathrm{mg} /$ day $)$ or Tenofovir ( $245 \mathrm{mg} /$ day) should be preferred to Adefovir ( $10 \mathrm{mg} /$ day) due to their higher antiviral potency (BIII).

Monotherapy with Lamivudine is not indicated in principle due to the risk of raising viral resistance $(\mathrm{AI})$. Telbivudine could be considered in patients with HBV DNA $<20,000,000 \mathrm{IU} / \mathrm{mL}$ [5] (BIII).

In both treatment strategies NAs should be first line therapy if treatment is started during an ALT flare with jaundice (CIII) and monotherapy with NAs should be continued for at least 12 months [6] after sero-conversion to anti-HBe and HBV DNA clearance (CIII).

\subsection{Aims and virological monitoring}

HBsAg loss, the ultimate goal of treatment, is rarely observed. The HBsAg/anti-HBs status should be defined every 12 months in all patients with undetectable HBV DNA by real time PCR on or off therapy.

\subsubsection{HBV DNA and virologic markers}

2.2.1.1. In patients on IFN.

- HBeAg/anti-HBe should be tested at 24 and 48 weeks of treatment and every 24 weeks after treatment until HBsAg loss (AI)

- There is no reliable predictor of response during therapy; HBV DNA higher than $2 \times 10^{5} \mathrm{IU} / \mathrm{mL}$ after 6 months has been associated with response failure (CIII).

- Therapy goals should be sero-conversion to anti HBe, normal ALT and serum HBV DNA <2000 IU/ml (inactive HBsAg carrier state) at the end of therapy (EOT) and 12 months post-treatment (sustained virologic response: SVR) (AI). Undetectable DNA by real time PCR is the most favourable outcome (high chance of HBsAg loss). SVR patients should be followed for ALT and HBV DNA at least every 6 months to confirm persistence of the inactive carrier state (AII).

2.2.1.2. In patients on $N A s[7,8]$. Regardless of treatment duration, therapy should achieve and maintain HBV DNA undetectable with highly sensitivity quantitative method and wide linear range (realtime PCR preferred). HBV DNA should be measured every 3 months. With Entecavir or Tenofovir, the time of control intervals after the first two negative consecutive tests can be doubled in the first 3 years of therapy (BII). Blood sampling protocols for safety are not related to the frequency of virological monitoring.

Finite duration therapy aims at suppression of HBV replication (undetectable HBV DNA) and anti-HBe sero-conversion while on therapy. The follow-up is the same as for IFN.

HBeAg/anti-HBe should be determined every 3 months, in order to plan NA withdrawal 12 months after sero-conversion and repeated every 6 months after treatment withdrawal, until HBsAg loss.

\section{Naive patients with HBeAg negative chronic hepatitis $B$}

The criteria for treatment remain:
- the stage of liver disease (fibrosis); this maintains a key decisional role (AII);

- the features of candidates; these are: "active" HBV replication, i.e. serum HBV DNA > $2000 \mathrm{IU} / \mathrm{mL}$, and abnormal ALT (higher than UNL) and/or fibrosis in liver biopsy corresponding to Ishak stage $\geq$ S3 or METAVIR stage $\geq$ F2 (S2).

Patients with these histologic and virologic features and normal or borderline ALT should also be considered for treatment. Subjects with Ishak stage $<\mathrm{S} 3$ and METAVIR stage $<\mathrm{F} 2$ can be monitored or treated with IFN or PEG-IFN (treatment is "possible") (AII), more compelling if inflammation corresponds to a grade $\geq A 2$ (ST2).

Patients with active replication and normal ALT should undergo ALT monitoring every 3-4 months and be evaluated using clinical and biochemical parameters, haematological parameters (platelets count, etc.) and non-invasive assessment (including ultrasound and transient elastography). Liver biopsy should be considered when disease is suspected by non-invasive evaluation; treatment is in order if biopsy shows significant fibrosis (Ishak stage $\geq$ S3 or METAVIR stage $\geq$ F2) (ST2).

\subsection{How to treat and what strategy to use}

Treatment should be proposed ("is optional") to patients with fibrosis corresponding to Ishak stage $\geq S 3$ or METAVIR stage $\geq F 2$; it is mandatory in more advanced fibrosis (Ishak $S \geq 4$ and METAVIR $F$ Z3) (AII) (ST2).

IFN [9] or long-term ("indefinite duration") NAs can be used. Since either has important limitations (PEG-IFN: low efficacy and significant side effects. NAs long-term therapy, possibly life-long with a risk of developing resistant mutants and of chronic toxicity), patients must be fully informed and should participate in the choice.

NAs require a protracted administration, possibly indefinite. This issue makes the indication to indefinite NAs administration controversial in young patients with less advanced fibrosis $(<\mathrm{F} 3$ METAVIR and <S4 Ishak) (ST2). NAs should be selected on the basis to the degree of HBV inhibition (antiviral efficacy), the risk of developing NA-resistant HBV mutants, the safety profile and the cost (AII).

First choice NAs in monotherapy are: (a) Entecavir; (b) Tenofovir; (c) Telbivudine only in patients with low baseline viremia $(<2,000,000 \mathrm{IU} / \mathrm{mL})$ (BIII). Lamivudine is not indicated due to the high risk of developing viral resistance. There are yet no data on a better efficacy of "de novo" combination therapy with a nucleoside and a nucleotide in naïve patients (ST2).

\subsection{End points of therapy, virological monitoring (new chapter ST2 update)}

With IFN, the response is defined by the decline and maintenance of HBV DNA to less than $2000 \mathrm{IU} / \mathrm{ml}$ and ALT normalization (inactive state), persisting at EOT and 12 months after therapy withdrawal (SVR) (BI). SVR patients should be followed with ALT, HBsAg/anti-HBs and HBV DNA determinations at least every 6 months, to monitor the persistence of the inactive carrier state or to establish the loss of HBsAg.

Discontinuation of IFN should be considered if HBVDNA declines to less than $1 \log _{10}$ after 3 months of therapy or remains at levels greater than $200,000 \mathrm{IU} / \mathrm{mL}$ after 24 weeks of treatment, as the probability of a SVR becomes low (CIII).

In HBeAg negative patients treated with NAs normal ALT and persistently undetectable HBV DNA by real time PCR are favourable outcomes (BI). HBV DNA testing should be performed as for $\mathrm{HBeAg}$ positive patients. 
Table 3

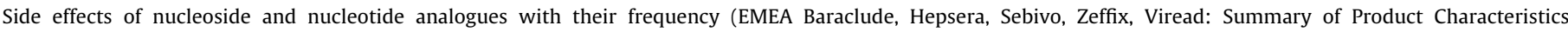
http://www.emea.europa.eu/humandocs/PDFs/last visit 28/10/2009).

\begin{tabular}{|c|c|c|c|c|c|}
\hline \multirow[t]{2}{*}{ Side effect } & \multicolumn{3}{|c|}{ Nucleoside analogues } & \multicolumn{2}{|c|}{ Nucleotide analogues } \\
\hline & Entecavir & Lamivudine & Telbivudine & Adefovir & Tenofovir \\
\hline Dizziness & $\mathrm{C}$ & & $\mathrm{C}$ & & $\mathrm{VC}^{\mathrm{a}}$ \\
\hline Gastrointestinal & $\mathrm{C}$ & & C & $\mathrm{C}$ & $\mathrm{VC}^{\mathrm{a}} / \mathrm{C}$ \\
\hline Headache & VC & & C & $\mathrm{C}$ & $\mathrm{C}$ \\
\hline Weakness & $\mathrm{C}$ & & $\mathrm{C}$ & VC & $\mathrm{C}$ \\
\hline Dyspnea & & & & & VI \\
\hline Rash and/or anaphylaxis & $\mathrm{U}$ & $\mathrm{C}$ & C & $\mathrm{C}$ & I \\
\hline Thrombocytopenia & & $\mathrm{U}$ & & & \\
\hline Somnolence & $\mathrm{C}$ & & & & \\
\hline Insomnia & $\mathrm{C}$ & & & & \\
\hline Cough & & & $\mathrm{C}$ & & \\
\hline Lactic acidosis & $\mathrm{U}$ & $U$ & $\mathrm{U}$ & & $\mathrm{I}^{\mathrm{a}}$ \\
\hline Hypophosphatemia & & & & $\mathrm{C}$ & $\mathrm{VC}^{\mathrm{a}}$ \\
\hline Serum creatinine increase & & & & VC & $\mathrm{I}^{\mathrm{a}}$ \\
\hline Acute tubular necrosis & & & & & $\mathrm{VI}^{\mathrm{a}}$ \\
\hline $\begin{array}{l}\text { Acute renal failure or Fanconi's syndrome or } \\
\text { proximal renal tubulopathy }\end{array}$ & & & & $\mathrm{U}$ & $\mathrm{I}^{\mathrm{a}}$ \\
\hline Nephritis (including interstitial nephritis) & & & & & $\mathrm{U}^{\mathrm{a}}$ \\
\hline Osteomalacia & & & & $\mathrm{U}$ & $\mathrm{U}^{\mathrm{a}}$ \\
\hline Pancreatitis & & $\mathrm{U}$ & & $\mathrm{U}$ & $\mathrm{I}^{\mathrm{a}}$ \\
\hline Serum CPK increase & & $\mathrm{C}$ & VC & & \\
\hline Myalgia & & $\mathrm{U}$ & NC & $\mathrm{U}$ & $\mathrm{U}^{\mathrm{a}}$ \\
\hline Rabdomyolysis & & & $\mathrm{U}$ & & $\mathrm{U}^{\mathrm{a}}$ \\
\hline Peripheral neuropathy & & & NC & & $\mathrm{U}^{\mathrm{a}}$ \\
\hline Serum amylase and/or lipase increase & & $\mathrm{U}$ & $\mathrm{C}$ & & \\
\hline Hypokaliemia & & & & & $\mathrm{U}^{\mathrm{a}}$ \\
\hline
\end{tabular}

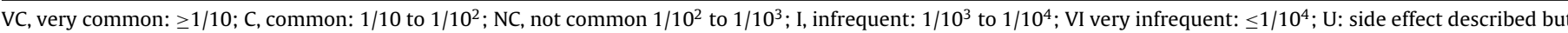
with unknown frequency.

a In human immunodeficiency virus (HIV)-infected patients.

\section{On- and off-therapy non-virological monitoring (new chapter ST2 update)}

Relevant co-morbid conditions should be assessed before treatment and during follow-up:

a. Interferon therapy: blood counts and liver function tests should be performed monthly while on treatment and at 1,3 and 6 months after treatment. TSH and non-organ specific autoantibodies should be determined every 3 months until 3 months after treatment $(\mathrm{AI})$;

b. NAs treatment: blood counts and liver function tests should be determined at least every 3 months (BII). It is recommended that creatinine clearance or estimated glomerular filtration rate (eGFR), calculated according to MDRD formula, is assessed at baseline in all patients to identify the need for dose adjustment. With renal impairment, these parameters should be assessed at least every 3 months during therapy (BII). In patients with no renal impairment creatinine should be assessed at least semestrally. Doses should be reduced in patients with renal insufficiency according to the manufacturers indications. eGFR should be monitored at least every month in patients given reduced NA doses and the dosage of NA should be adjusted accordingly. Non virological monitoring of patients assuming NA is summarized in Fig. 3.

Side effects of NA are summarized in Table 3 [10-12]. Side effects are rare and minor with Lamivudine, Entecavir and Telbivudine(AI). The administration of PEG-IFN together with Telbivudine must be avoided because of an increased risk of peripheral neuropathy [11] (CIII)

Drugs associated with muscle toxicity (i.e. statins, fibrates cyclosporin, etc.) should be avoided in patients on Telbivudine (CIII).

Potential nephrotoxicity related to tubular excretion is shared by all NAs except Telbivudine (excreted only by glomerular filtra- tion). The nephrotoxic potential is higher for Adefovir and Tenofovir [12]. Patients taking these NAs should use cautiously potentially nephrotoxic drugs (CIII); they should avoid non-steroidal antiinflammatory drugs (CIII).

In patients with grade III renal insufficiency (i.e. eGFR $<60 \mathrm{~mL} / \mathrm{min} / 1.73 \mathrm{~m}^{2}$ b.s.a.) Tenofovir and Adefovir should be used only if benefits exceed potential risks. As per the manufacturer indications in patients on Tenofovir and Adefovir treatment a urine dipstick and plasma phosphorus and creatinine with the measure of Glomerular Filtration Rate should be obtained every month during the first year and every 3 months thereafter (CIII). In patients with serum phosphate persistently $<0.64 \mathrm{mmol} / 1(1.98 \mathrm{mg} / \mathrm{dL})$, an underlying renal tubular injury or Fanconi's syndrome should be excluded (by the determination and monitoring in plasma and urine of: phosphorus, calcium, proteins with electrophoresis and glucose; with an urine dipstik, serum bicarbonate and uric acid).

Tenofovir was reported to negatively influence bone metabolism in HIV/HBV patients [13]. Therefore in patients candidate to Tenofovir treatment caution should be taken to exclude important bone alterations. In particular patients with chronic hypophosphatemia, persistent back pain (particularly in the upright position) and or marked height reduction, bone metabolism should be assessed and dorsal, lumbar X-rays and DEXA performed as appropriate.

Exposure to NAs has been associated with lactic acidosis in the treatment of HIV infection and in the treatment of hepatitis B [14]. Symptoms occurring in lactic acidosis are heterogeneous, however digestive symptoms are the most common: nausea and vomiting, abdominal pain, asthenia, painful dysesthesias, muscular weakness, anorexia, weight loss, fever or hypothermia, dyspnea. Tachypnea and hepatomegaly are the typical but not specific findings at physical examination. The laboratory shows elevated serum lactic acid and low serum bicarbonate concentrations, elevation of transaminases, amylase, lipase, lactate dehydrogenase and creatinine phosphokinase. 
Entecavir and Adefovir are classified by the Food and Drug Administration (FDA) as pregnancy risk Category C; their use is precluded in pregnancy. Tenofovir and Telbivudine are in Category B (birth defects rate of $1.5 \%$ - second trimester use - and $2.3 \%$ first trimester use - similar to the background rate) and are considered safe in pregnancy [15]. Although in class C, Lamivudine was associated with a risk of birth defects no higher than the baseline background (2.2-2.4\%).

\section{Patients without optimal response to NAs (new chapter ST2 update)}

\subsection{Definitions [16]}

1) Primary non-response to a NA: decline of HBV DNA to less than 1 $\log$ from baseline after 3 months of treatment

2) Partial virologic response to a NA: HBV DNA detectable after 6 months of treatment with Lamivudine or Telbivudine, or after 12 months of treatment with Tenofovir, Adefovir, or Entecavir (AII)

3) Virologic breakthrough: an increase of 1 log of HBV DNA over the nadir, confirmed after 1 month, in a treatment-adherent patient

Patients with a NA and with primary non-response, or partial virologic response or a breakthrough to a NA must be considered for treatment adjustment [16]. Genotypic resistance testing is useful for therapeutic guidance (BII). It should be tested before changing or restarting NA in patients previously treated with antiviral drugs.

\subsection{Adaptation of therapy in patients with primary}

non-response, partial virologic response or breakthrough with or without detectable genotypic resistance to NA

When an adherent patient on NA shows a primary non-response or a partial virologic response or a breakthrough with or without genotypic resistance, a combination therapy should be considered [16-20]

Therapy should be individualised, based on genotypic assay.

Sensitivity to Entecavir is reduced in patients resistant to Lamivudine or Telbivudine; resistance to these drugs can be rescued only with Tenofovir. Tenofovir resistance has not been described so far.

Suggestions for treatment adaptation while waiting for genotyping are, in patients treated with:

1) Lamivudine: Add-on of Tenofovir (AII);

2) Adefovir: switch to Tenofovir, with addition of Telbivudine or Entecavir or Lamivudine or Emtricitabine in HIV coinfected persons (BII). Some experts suggest to prescribe Lamivudine or Emtricitabine only after the exclusion of HBV mutations in position 181 by genotypic tresting (CIII);

3) Entecavir: Add-on Tenofovir (CIII)

4) Adefovir and Lamivudine: switch Adefovir to Tenofovir, switch Lamivudine to Entecavir $1 \mathrm{mg} /$ day (CIII)

Of note, safety and efficacy data on the combination of Tenofovir with Lamivudine or Emtricitabine (not yet licensed for the use in HBV mono-infected patients) were obtained mostly in HIV infected subjects. Data on the other combinations are anecdotal. The current data show that resistance to Tenofovir or Entecavir is very uncommon even after 3 years of monotherapy. Therefore prolonging treatment until HBV DNA clearance for an additional year could be considered in patients on monotherapy with Tenofovir or Entecavir with detectable HBV DNA after 48 weeks of treatment, provided that they: (a) had very high baseline viremia

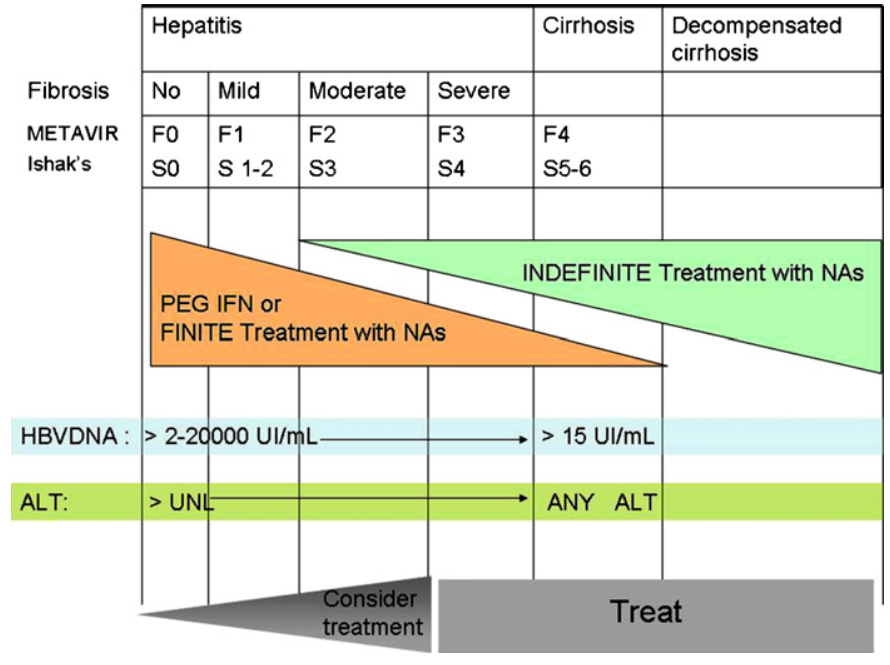

Fig. 1. The "Stresa Paradigm" summarizing the indications for treatment of patients with $\mathrm{HBeAg}$ positive hepatitis B with or without cirrhosis. NA: nucleoside/tide analogues.

(>20,000,000 IU $/ \mathrm{mL}$ ); b) did not develop a breakthrough or resistance to these drugs; (c) exhibit a progressive decrease of HBV DNA.

\section{Patients with cirrhosis (HBeAg positive and negative)}

Treatment is mandatory in patients with compensated or decompensated cirrhosis and detectable HBV DNA, independently of ALT levels (ST2). Patients with no HBV DNA detectable by current sensitive tests should be monitored (BIII).

Before treatment considerations should be given to (ST2):

- liver function, whether compensated or decompensated;

- presence of oesophago-gastric varices;

- age;

- HBV DNA levels;

- viral genotype in patients candidating for IFN therapy;

- AST/ALT levels;

- co-morbidities and co-factors potentially worsening liver disease;

- prospect of liver transplant;

\subsection{How to treat and what strategy to use}

\subsubsection{Compensated cirrhosis (HBeAg positive or negative)}

PEG-IFN (or standard IFNs) should be considered only in patients without a history of decompensation, with no oesophago-gastric varices and with predictors of favourable response (BII). As interferon may induce hepatic flares, it should be used with caution (CIII). Monitoring should be instituted during and after therapy with PEG-IFN to allow rapid switching to NAs (ST2).

Figs. 1 and 2 summarize updated recommendations across the clinical spectrum of HBV diseases.

NAs can be considered in all patients with cirrhosis (ST2). First line options are (BIII): (a) monotherapy with Entecavir; (b) monotherapy with Tenofovir; (c) monotherapy with Telbivudine in patients with HBV DNA $<2,000,000 \mathrm{IU} / \mathrm{mL}$ (BIII). Lamivudine monotherapy is not indicated for the risk of raising resistance (AI). Adefovir monotherapy is limited by its slow potency; monotherapy with tenofovir is preferred. NAs in combination could be considered when decompensation appears imminent and/or in the presence of high HBV DNA levels, in order to minimize the risk of resistance (ST2). 


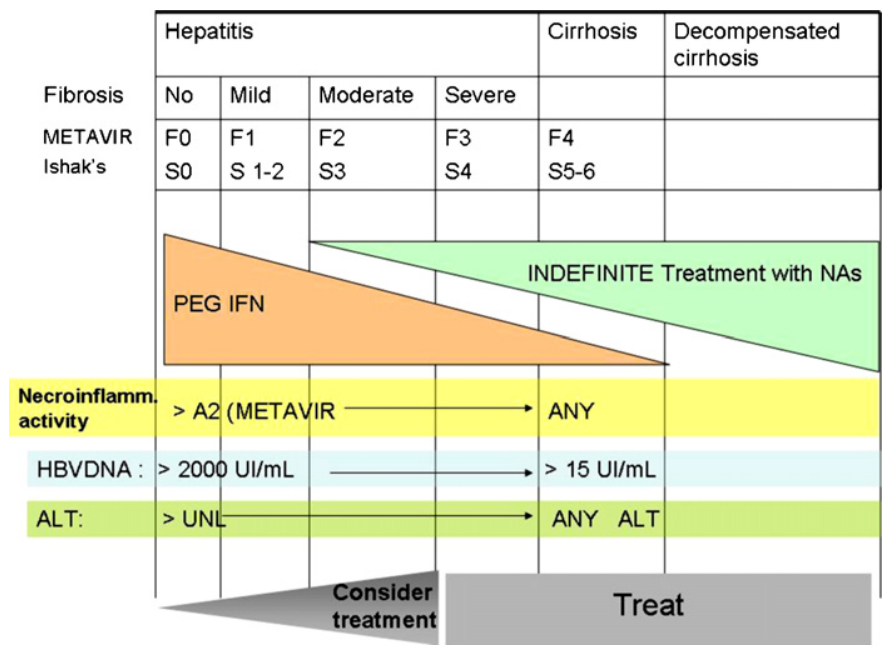

Fig. 2. The "Stresa Paradigm" summarizing the indications for treatment of patients with $\mathrm{HBeAg}$ negative hepatitis B with or without cirrhosis. NA: nucleoside/tide analogues.

\subsubsection{Decompensated cirrhosis}

In cirrhotics experience is limited to lamivudine and adefovir in mono or combined therapy. At the time of the update, data on Telbivudine monotherapy and Entecavir, Tenofovir, Telbivudine in combinations are evaluated in clinical trials (CIII).

Recent studies on the treatment of decompensated cirrhosis with Entecavir or Tenofovir showed efficacy and safety [21-23]. Lactic acidosis has occurred while on entecavir in patients with liver and multi-organ failure [14]. Renal tolerance with tenofovir was acceptable. Therefore it seems plausible to use the most potent NAs as Entecavir or Tenofovir also in these patients (BIII) (ST2).

In patients eligible for liver transplant (LT) treatment with NAs should be started in collaboration with a reference transplant centre and aimed at: (a) control of the risk of clinical deterioration (virologic monitoring is mandatory with prompt treatment of breakthroughs) (AII); (b) reduction of viremia as low as possible before transplantation to reduce the risk of hepatitis $B$ reactivation (AII); (c) prevention of the emergence of HBV mutants resistant to NAs (ST2).

After transplantation, the standard of prophylaxis is a combination of NAs and anti-HB immunoglobulins (HBIG) (AII). Life-long prophylaxis is required (BI). Post-LT experience has been yet achieved only with lamivudine and/or Adefovir. Data on Entecavir, Tenofovir and Telbivudine are few. It seems nevertheless plausible

\begin{tabular}{|c|c|}
\hline Test & Frequency \\
\hline $\begin{array}{l}\text { Liver enzimes \& Complete Blood } \\
\text { counts }\end{array}$ & 0,3 months then every $3-6$ months \\
\hline $\begin{array}{l}\text { Creatinine with eGFR calculation by } \\
\text { MDRD formula }\end{array}$ & 0,6 months then every 6 months ${ }^{*}$ \\
\hline Anti HIV & $\begin{array}{l}\text { At baseline in all pts assuming } \\
\text { Tenofovir, or Entecavir or Lamivudine. } \\
\text { Every year in pts with exposure to risk } \\
\text { factors for HIV transmission. }\end{array}$ \\
\hline CPK & $\begin{array}{l}0,1,3 \text { months then every } 3 \text { months in } \\
\text { pts assuming Telbivudine }\end{array}$ \\
\hline $\begin{array}{l}\text { Creatinine with e GFR calculation by } \\
\text { MDRD formula phosphorus and urine } \\
\text { dripstik }\end{array}$ & $\begin{array}{l}\text { Every month during the } 1^{\text {st }} \text { year and } \\
\text { then every } 3 \text { months in pts assuming } \\
\text { Tenofovir or Adefovir }\end{array}$ \\
\hline
\end{tabular}

Fig. 3. Summary of non-virological monitoring in patients assuming nucleosides/tides analogues. to combine after transplantation HBIG with the same last generation NA used before LT CIII) (ST2).

Monitoring is the same as in non-cirrhotics; liver function tests should be performed more frequently in patients on NA in particular in decompensated cirrhosis and LT candidates. In decompensated cirrhosis or liver transplants eGFR is not well validated; dose adjustments and monitoring of renal toxicity should be assessed on creatinine clearance measured in $24 \mathrm{~h}$ urine collections (ST2).

\subsubsection{Hepatocellular carcinoma (new chapter from ST2 update)}

An efficient antiviral therapy with durable suppression of the viral load reduces the risk of progression to cirrhosis and consequently to development of cirrhosis-related HCC [(B III)

However a risk of HCC remains in treated patients with cirrhosis. It is reduced in naive patients treated with NAs who achieve HBV DNA clearance but resumes at the time of clinical resistance (also in presence of rescue therapy) or after the first evidence of HCC $[25,26]$ even if effectively treated with the loco-regional therapy [27] (BIII).

Accordingly, in prospective of HCC prevention: (a) therapy should aim at a complete virologic response (HBV DNA negative with sensitive assays) in cirrhotics treated with NAs; (b) the response should be maintained over time with strict monitoring and rational therapy of resistance; (c) continuous surveillance for HCC should be mandatory (BII); (d) liver transplantation should be considered after the first evidence of HCC (BIII) (ST2).

\section{Conflict of interest statement}

None declared.

\section{Acknowledgment}

We thank Marco Borderi from the Infectious Diseases section of the Department of Clinical and Experimental Medicine of the University of Bologna for his contribution on "ON- and OFF-THERAPY NON-VIROLOGICAL MONITORING".

\section{Appendix A. Supplementary data}

Supplementary data associated with this article can be found, in the online version, at doi:10.1016/j.dld.2010.10.014.

\section{References}

[1] Carosi G, Rizzetto M. Treatment of chronic hepatitis B: recommendations from an Italian workshop. Dig Liver Dis 2008;40:603-17.

[2] Buster EH, Hansen BE, Lau GK, et al. Factors that predict response of patients with hepatitis B e antigen-positive chronic hepatitis B to Peginterferon-alpha. Gastroenterology 2009;137:2002-9.

[3] Marcellin P, Heathcote EJ, Buti M, et al. Tenofovir disoproxil fumarate versus adefovir dipivoxil for chronic hepatitis B. N Engl J Med 2008;359:2442-55.

[4] Tenney DJ, Rose RE, Baldick CJ, et al. Long-term monitoring shows hepatitis $\mathrm{B}$ virus resistance to entecavir in nucleoside-naïve patients is rare through 5 years of therapy. Hepatology 2009;49:1503-14.

[5] Zeuzem S, Gane E, Liaw YF, et al. Baseline characteristics and early on-treatment response predict the outcomes of 2 years of telbivudine treatment of chronic hepatitis B. J Hepatol 2009;51:11-20.

[6] Lee HW, Lee HJ, Hwang JS, et al. Lamivudine maintenance beyond one year after $\mathrm{HBeAg}$ seroconversion is a major factor for sustained virologic response in HBeAg-positive chronic hepatitis B. Hepatology 2010;51:415-21.

[7] Pawlotsky JM, Dusheiko G, Hatzakis A, et al. Virologic monitoring of hepatitis B virus therapy in clinical trials and practice: recommendations for a standardized approach. Gastroenterology 2008;134:405-15.

[8] Lampertico P. Partial virological response to nucleos(t)ide analogues in naïve patients with chronic hepatitis B: From guidelines to field practice. J Hepatol 2009;50:644-7.

[9] Marcellin P, Bonino F, Lau GK, et al. Sustained response of hepatitis B e antigen-negative patients 3 years after treatment with peginterferon alpha-2a. Gastroenterology 2009;136:2169-79, e1-4.

[10] Fontana RJ. Side effects of long-term oral antiviral therapy for hepatitis B. Hepatology 2009;49(5 Suppl.):S185-95. 
[11] Fleischer RD, Lok AS. Myopathy and neuropathy associated with nucleos(t)ide analog therapy for hepatitis B. J Hepatol 2009;51:787-91.

[12] Ha NB, Ha NB, Garcia RT, et al. Renal dysfunction in chronic hepatitis B patients treated with adefovir dipivoxil. Hepatology 2009;50:727-34.

[13] Woodward CL, Hall AM, Williams IG, et al. Tenofovir-associated renal and bone toxicity. HIV Med 2009;10:482-7.

[14] Lange CM, Bojunga J, Hofmann WP, et al. Severe lactic acidosis during treatment of chronic hepatitis B with entecavir in patients with impaired liver function. Hepatology 2009;50:2001-6.

[15] Buchanan C, Tran TT. Management of chronic hepatitis B in pregnancy. Clin Liver Dis 2010;14:495-504.

[16] Zoulim F, Locarnini S. Hepatitis B virus resistance to nucleos(t)ide analogues. Gastroenterology 2009;197:1593-608.

[17] Cho SW, Koh KH, Cheong JY, et al. Low efficacy of entecavir therapy in adefovirrefractory hepatitis B patients with prior lamivudine resistance. J Viral Hepat 2010;17:171-7.

[18] van Bömmel F, de Man RA, Wedemeyer H, et al. Long-term efficacy of tenofovir monotherapy for hepatitis B virus-monoinfected patients after failure of nucleoside/nucleotide analogues. Hepatology 2010;51:73-80.

[19] Gaia S, Barbon V, Smedile A, et al. Lamivudine-resistant chronic hepatitis B: an observational study on adefovir in monotherapy or in combination with lamivudine. J Hepatol 2008;48:540-7.
[20] Berg T, Marcellin P, Zoulim F, Moller B, et al. Tenofovir is effective alone or with emtricitabine in adefovir-treated patients with chronic-hepatitis $B$ virus infection. Gastroenterology 2010;139:1207-17.

[21] Schiff E, Simsek H, Lee WM, et al. Efficacy and safety of entecavir in patients with chronic hepatitis B and advanced hepatic fibrosis or cirrhosis. Am J Gastroenterol 2008;103:2776-83.

[22] Fontana RJ. Entecavir in decompensated HBV cirrhosis: the future is looking brighter. J Hepatol 2010;52:147-9.

[23] Tan HH, Martin P. Management of end-stage liver disease in chronic hepatitis B. Clin Liver Dis 2010;14:477-93.

[24] Papatheodoridis GV, Lampertico P, Manolakopoulos S, Lok A. Incidence of hepatocellular carcinoma in chronic hepatitis B patients receiving nucleos(t)ide therapy: a systematic review. J Hepatol 2010;53:348-56.

[25] Elefsiniotis I, Buti M, Jardi R, et al. Clinical outcome of lamivudine-resistant chronic hepatitis B patients with compensated cirrhosis under adefovir salvage treatment. Importance of HCC surveillance. Eur J Intern Med 2009;20:478-81.

[26] Hann HW, Bergin D, Coben R, Dimarino AJ. Prevention of new hepatocellular carcinoma with concomitant antiviral therapy in chronic hepatitis B patients whose initial tumor was successfully ablated. Int J Cancer 2011;128:739-42.

[27] Li N, Lai EC, Shi J, et al. A comparative study of antiviral therapy after resection of hepatocellular carcinoma in the immune-active phase of hepatitis B virus infection. Ann Surg Oncol 2010;17:179-85. 